\section{Nuevos Impresores para la Revista Médica de Chile}

\section{IKU Ltda. is the new printing agency for Revista Médica de Chile}

En diciembre de 2009 debía caducar el contrato entre la Sociedad Médica de Santiago-Sociedad Chilena de Medicina Interna, productores de la Revista Médica de Chile, y Gaete y Cía. Ltda., como sus diseñadores gráficos e impresores. Este contrato empezó a regir desde enero de 1995, con una duración establecida por cinco años, con renovación automática por períodos similares, a menos que una de las partes contratantes decidiera darle fin para establecer nuevas condiciones. Los editores de la Revista hicimos presente oportunamente a la Mesa Directiva de la Sociedad que, en nuestra opinión, era conveniente aprovechar el plazo quinquenal de renovación del contrato (enero de 2010) para modificarlo, acortando su duración e incluyendo en él condiciones que no existían cuando se redactó por primera vez, en 1994, pero que ahora inciden en el proceso de impresión y en el costo de la publicación. Además, la inminente implementación del manejo de manuscritos a través de la Internet podría causar cambios - positivos o negativos- en el costo de la edición e impresión de la Revista.

Mientras sucedía lo antedicho, Elsevier, una de las mayores empresas editoras de revistas científicas en el mundo, ofreció a la Sociedad Médica de Santiago hacerse cargo del proceso editorial y el diseño gráfico de la Revista Médica de Chile, manejándolos vía Internet desde su oficina en Barcelona, para entregar cada número mensual en versión digitalizada para ser impreso en Chile. Además, la Revista accedería a otras facilidades que otorga Elsevier para el análisis periódico de la "visibilidad" del contenido de las revistas a su cargo, su indización y difusión internacional. Al aceptar esta oferta, la Sociedad Médica de Santiago tendría que pagar los servicios de Elsevier y, además, los de la imprenta que imprimiría la Revista en Chile. Ello supera ampliamente los costos actuales de producción de la Revista, por lo cual la oferta de Elsevier fue declinada.

La Mesa Directiva de la Sociedad Médica de Santiago invitó a presentar propuestas para el diseño gráfico y la impresión de la Revista a Gaete y Cía. Ltda. y a la Editorial IKU Ltda., conocidas por su experiencia en el ramo y por ser impresoras de una alta proporción de las revistas médicas chilenas. Ambas empresas debieron considerar las exigencias especificadas en un documento elaborado por los editores de la Revista Médica de Chile, que incluye el diseño de la revista y su impresión en papel, más la entrega de una versión digitalizada que facilite al Programa SciELO de la Comisión Nacional de Investigación Científica y Tecnológica (CONICYT) reproducir la Revista en versión electrónica. Las empresas postulantes establecieron sus respectivos costos para el diseño y la impresión de la Revista y sus propuestas para la distribución de los recursos recolectados mediante la contratación de avisos comerciales. La Mesa Directiva de la Sociedad Médica de Santiago consideró financieramente más ventajosa la propuesta de Editorial $I K U$ Ltda. y se generó un contrato por dos años, renovable por lapsos similares, el cual fue firmado por el Dr. Héctor Ugalde Prieto, Presidente de la Sociedad Médica de Santiago-Sociedad Chilena de Medicina Interna, y la Sra. María Cristina Illanes Holch en representación de Editorial IKU Ltda.

Un resumen de estos antecedentes fue expuesto por la Mesa Directiva al Directorio de la Sociedad, en sesión del 15 de diciembre de 2009, recibiendo la aprobación de su gestión y del acuerdo adoptado.

Posteriormente, los editores de la Revista Médica de Chile nos reunimos con los Sres. Pedro y Jorge Gaete para agradecer su eficiente labor como impresores de esta Revista durante quince años, durante los cuales hemos apreciado la responsabilidad y profesionalismo con que ejecutan su trabajo. Cada dificultad surgida en este proceso se superó con su buena disposición y el orgullo de ser impresores de una de las pocas revistas técnicas profesionales con publicación mensual, en nuestro país. Esta frecuencia de publicación hace por sí sola más compleja la interacción entre los editores y su personal de apoyo, por una parte, y los impresores y sus labores contratadas, por la otra. La calidad del trabajo de los Sres. Gaete merece el reconocimiento de los directivos de la Sociedad y, muy en particular, de los editores de la Revista Médica de Chile.

Las reuniones de planificación sostenidas con los representantes de Editorial IKU Ltda. han sido auspiciosas. En este número de la Revista Médica de Chile iniciaron su gestión como diseñadores gráficos e impresores. Sus antecedentes profesionales brindan garantías de responsabilidad y eficiencia, que esperamos se reflejarán en la satisfacción de los suscriptores y lectores de la Revista. Compartimos la visión de futuros cambios de formato que hagan cada vez más grato recorrer su contenido, aquel que refleja las ambiciones, gustos y expectativas de quienes nos envían sus manuscritos.

Humberto Reyes B., Editor Jefe. Joaquín Palma H. y Max Andresen H., Editores Asociados. 